\title{
The psychiatric effects of varenicline on patients with depression
}

\author{
EYH Yeung ${ }^{*}$, S Long, BL Bachi, J Lee, Y Chao \\ From International Conference for Healthcare and Medical Students (ICHAMS) 2013 \\ Dublin, Ireland. 11-12 October 2013
}

\section{Background}

Varenicline is currently the most effective smoking cessation medication. Pre-marketing clinical trials excluded participants with psychiatric disorders, such as major depressive disorders. This study investigated the psychiatric effects of varenicline among patients with depression.

\section{Methods}

On 18 December 2012, a systematic search was performed using Medline with the following search terms: 1) varenicline and 2) depression. The search was limited to English articles, case reports, and original clinical studies. From the 58 retrieved documents, 15 articles were used in this review.

\section{Results}

The first case report on the effects of varenicline on patients with depression was published in June 2008. A man experienced an acute exacerbation of depressive symptoms, which resolved after he stopped his varenicline treatment. [1] Since then, there were 8 other case reports that described exacerbation of psychiatric symptoms in patients with depression taking varenicline [2-9]. Two of those case studies suggested the use of sertraline [7] and bupropion [8] to treat exacerbation of depressive symptoms associated with varenicline. In contrast, varenicline was shown to improve the affective symptoms of a smoker who developed depression and suicidal tendencies during previous cessation attempts [10]. There were 3 observational studies on patients with depression taking varenicline: 1) a one-year follow-up study on 112 smokers showed an association between increased Beck Depression Inventory score and continued smoking after 12 weeks of varenicline [11]; 2) an open-labelled study showed significant improvement in mood in 110 outpatient smokers

\footnotetext{
College of Medical and Dental Sciences, The University of Birmingham, Birmingham, United Kingdom
} ing cessation trial on 217 varenicline users showed that depressive symptoms at the time of varenicline initiation (measured by Patient Health Questionnaire-2) were associated with suicidal ideation. [13] There were 2 clinical trials on patients with depression taking varenicline, with both of them showing worsening of psychiatric symptoms. $[14,15]$ Neither of the trials were placebo-controlled.

\section{Conclusions}

Despite some inconsistencies, the findings suggested that varenicline could worsen psychiatric symptoms in patients with depression. Clinicians should be advised to closely monitor patients with a history of depression on varenicline, although there were no studies on how to treat those patients. Bias and uncontrolled confounders potentially affected previous studies, and thus, a doubleblinded placebo-controlled trial is needed to demonstrate the efficacy and side effects of varenicline on patients with depression.

\section{Published: 14 January 2015}

\section{References} with varenicline. Am J Psychiatry 2008, 165:774.

2. Pumariega AJ, Nelson R, Rotenberg L: Varenicline-induced mixed mood and psychotic episode in a patient with a past history of depression. CNS Spectr 2008, 13:511-514.

3. Pirmoradi $P$, Roshan $S$, Nadeem SS: Neuropsychiatric disturbance after initiation of varenicline in a patient with a history of alcohol abuse and major depression. Am J Health Syst Pharm 2008, 65:1624-1626.

4. Lyon GJ: Possible varenicline-induced paranoia and irritability in a patient with major depressive disorder, borderline personality disorder, and methamphetamine abuse in remission. J Clin Psychopharmacol 2008, 28:720-721.

5. Raidoo BM, Kutscher EC: Visual hallucinations associated with varenicline: a case report. J Med Case Rep 2009, 3, 7560-1947-3-7560.

6. Cantrell M, Argo T, Haak L, et al: Adverse neuropsychiatric events associated with varenicline use in veterans: a case series. Issues Ment Health Nurs 2012, 33:665-669. popkin MK: Exacerbation of recurrent depression as a result of treatment 
7. Baran XY, Docherty JP: Rapid and sustained response to a single dose of sertraline in a patient with newly emergent depression during varenicline-assisted smoking cessation. CNS Spectr 2010, 15:148-151.

8. Karam-Hage M, Shah KR, Cinciripini PM: Addition of bupropion SR to varenicline alleviated depression and suicidal ideation: a case report. Prim Care Companion J Clin Psychiatry 2010, 12, 10.4088/PCC.09100800blu.

9. Hussain $\mathrm{S}$, Kayne $\mathrm{E}$, Guwanardane $\mathrm{N}$, et al: Varenicline induced mania in a 51 year old patient without history of bipolar illness. Prog Neuropsychopharmacol Biol Psychiatry 2011, 35:1162-1163.

10. Grosshans M, Mutschler J, Hermann D, et al: Reduced affective symptoms during tobacco dependence treatment with varenicline. Addiction 2009, 104:859-861.

11. Grassi MC, Enea D, Ferketich AK, et al: Effectiveness of varenicline for smoking cessation: a 1-year follow-up study. J Subst Abuse Treat 2011, 41:64-70.

12. Philip NS, Carpenter LL, Tyrka AR, et al: Varenicline augmentation in depressed smokers: an 8-week, open-label study. J Clin Psychiatry 2009, 70:1026-1031

13. Cowan CM, Wink JS, DeZee KJ: Use of the Patient Health Questionnaire-2 to predict suicidal ideations in patients taking varenicline. Am J Addict 2012, 21:356-362.

14. McClure JB, Swan GE, Jack $L$, et al: Mood, side-effects and smoking outcomes among persons with and without probable lifetime depression taking varenicline. J Gen Intern Med 2009, 24:563-569

15. McClure JB, Swan GE, Catz SL, et al: Smoking outcome by psychiatric history after behavioral and varenicline treatment. J Subst Abuse Treat 2010, 38:394-402.

doi:10.1186/1753-6561-9-S1-A31

Cite this article as: Yeung et al.: The psychiatric effects of varenicline on patients with depression. BMC Proceedings 2015 9(Suppl 1):A31.

\section{Submit your next manuscript to BioMed Central and take full advantage of:}

- Convenient online submission

- Thorough peer review

- No space constraints or color figure charges

- Immediate publication on acceptance

- Inclusion in PubMed, CAS, Scopus and Google Scholar

- Research which is freely available for redistribution

Submit your manuscript at www.biomedcentral.com/submit
Biomed Central 